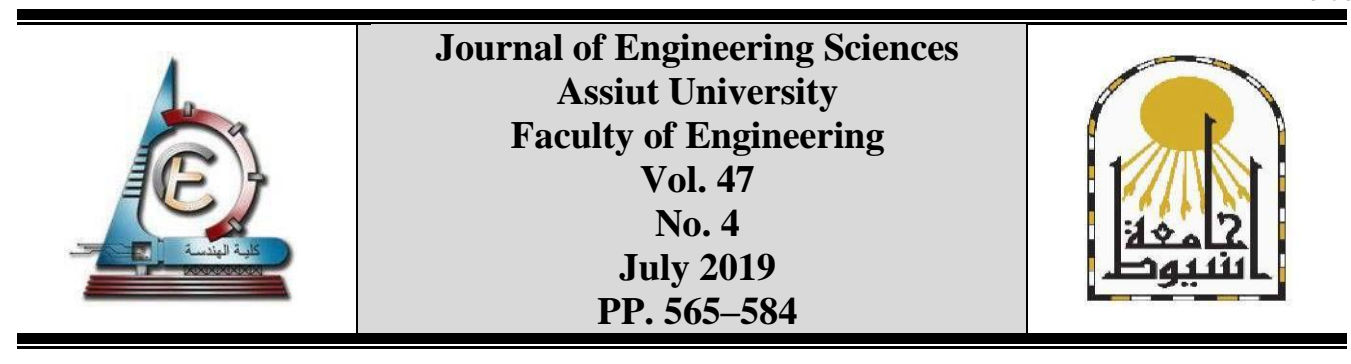

\title{
SUSTAINABLE DEVELOPMENT AND GOVERNANCE IN SAUDI CITIES
}

\author{
Khalid Nasralden Mandeli \\ King Abdulaziz University, Jeddah, Saudi Arabia. \\ Email address: joodek2002@yahoo.com,kmandeli@kau.sa.edu
}

Received 5 March 2019; Accepted 23 March 2019

\begin{abstract}
The dramatic development of urban and rural areas in Saudi Arabia over the last five decades resulted in enormous stresses on natural and man-made habitats across several regions. This led to serious environmental problems which pose challenges for environmental sustainability. Although the government has made steady progress in environmental protection by establishing a legal regime to handle it, sustainable development has not yet been achieved due to inadequate urban planning and management schemes that inadequately address accelerated urbanization. This paper explores the attitudes of experienced professionals and officials in urban and environmental planning towards the quality of environmental sustainability in Saudi cities. This research aims to discuss institutional arrangements and mechanisms for environmental sustainability, highlighting key challenges and opportunities to shape action. The researcher also discusses recent reform initiatives of Saudi Vision 2030 promoting urban governance. Broadly speakinghe, the investigation - which is based on extensive literature review, documentary analysis and a qualitative survey - notes that, a holistic approach to sustainability governance is urgently needed. This can help integrate the agendas of the multiple actors and agencies involved.
\end{abstract}

Keywords: Urbanization; urban planning; environmental sustainability; sustainable development; urban governance; Saudi Arabia

\section{Introduction}

Sustainable development has recently become central to international policy discussions, due to formidable issues stemming from the increasing complexity of societal challenges. Although global efforts for sustainable development have progressed through coordinated strategic actions, empirical evidence shows socio-economic and environmental trends indicating that it remains incomplete. Many countries still suffer immense environmental problems from intensified urban development overriding environmental protection, with massive exploitation of natural resources indifferent to future generations.

Sustainable development is complex. It considers all economic, environmental and social aspects in decision-making processes. This creates an institutional difficulty, first because it requires proactive government actions and second because it contradicts traditional policymaking. Integrating policy goals between different governmental bodies is difficult, not only from lack of spatial planning and development policies, but also because of the absence of effective governance and institutional arrangements to implement the 
2014 UN Sustainable Development Goals (SDGs). There are few institutional and administrative capacities for coherent holistic frameworks throughout the state machinery due to conflicting priorities between agencies which are averse to sharing responsibilities.

The historical development of Saudi towns and cities shows recent dramatic physical transformations owing to rapid demographic, social and economic growth. To regulate sustainable urban development while alleviating negative effects on public health and natural environments, the government has embarked on several reforms. After 1932, it established ministries and public agencies and joined several global conventions. Since the first National Development Plan (1970-1974), further 5-year plans have focussed on national priorities, making effective tools for sustainable development. Wide-ranging spatial, social and economic developments have raised living standards. Numerous sustainable development plans have been adopted. These have played major roles in environmental sustainability, but despite repeated promises many natural and man-made habitats still suffer damage. This includes loss of agricultural lands and natural resources, high energy and water consumption, air pollution, traffic congestion, inadequate basic services and unregulated settlements. This has been attributed to poor holistic spatial planning, ineffective governance, and a lack of institutional capacity.

In April 2016, ambitious economic reform was promoted under Saudi Vision 2030. The National Transformation Programme 2020 (NTP) was launched by the Council of Economic and Development Affairs (CEDA). This ambitious economic and administrative reform project aims to preserve and develop all available resources. It calls for effective governance by developing institutional capacities while adopting sustainable regulatory practices. This research sheds light on institutional arrangements and environmental governance mechanisms, highlighting Saudi Vision 2030. The government has made significant efforts towards environmental sustainability by enacting several rules and policies; but evidence suggests that poor urban governance and weaknesses in the design and enforcement of land development policies and environmental laws threaten these.

\section{Sustainability and governance: background}

\subsection{Urbanization and sustainable urban development}

Rapidly growing populations created a dramatic increase in large cities, which expanded to unprecedented sizes. This put enormous stresses on the quality of urban and rural environments, challenging sustainable development. In response to growing concern over socio-economic impact on the environment, two strands of sustainable development have emerged to protect the environment and natural resources. The first stance in the debate about environment vs. development (advocated by environmentalists) is called 'strong', the other (advocated by modern ecologists) 'weak' [1]. Based on a 'green theory of value', strong stance advocates say cities generate environmental costs and most natural resources cannot be replenished. If current urban areas consume resources while ignoring future needs, serious environmental and socio-economic problems will spread: achieving sustainability means rejecting development in favour of the environment [2].

This concern for environmental protection was emphasized in the 1972 United Nations Conference on the Human Environment. It was also raised in Paris European Summit held that October to heighten awareness of environmental issues in the European Community. Through these, a list was announced of environmental protection principles, to prevent 
ecological damage and guide future development. This initiated several environmental policies and programmes, including the United Nations Environment Programme (UNEP), the first Environmental Action Programme (EAP 1) of the European Council (1973-1976), and the World Conservation Strategy, 'Caring for the Earth', of the International Union for the Conservation of Nature (1980) (IUCN) [3, 4].

Others believe that human regenerative development aided by market incentives and public policies can achieve sustainability and compensate technologically for natural resource depletion [5]. This stance (weak urban development based on 'ecological modernisation' for environmental protection) should be a prerequisite for decision-making on interdependent socio-economic development. The 1987 report from the UN-appointed Brundtland Commission was advocated by the Fourth Environmental Action Programme adopted by the European Commission for the period 1987-1992.

The Brundtland Report, 'Our Common Future', was the first global step to recognize sustainable development. It was accepted internationally because it emphasized efficient resource allocation for socio-economic development and the urgent need to embrace future growth [6]. Sustainable approaches require 'development that meets the needs of the present without compromising the ability of future generations to meet their own needs' [7].

The change in political debate from environmental issues to broader environmental and socio-economic development has encouraged sustainable development within environmental policy [8]. This has produced a broad range of policies to improve scientific and technological knowledge of ecological problems. It has also necessitated further change in environmental policies and legislation announced by intergovernmental bodies (e.g. the United Nations, the International Union for the Conservation of Nature, and the Council of the European Union) in treaties and strategies such as in Agenda 21 (1992), and the UN goals of 2014. Sustainable development is now normative for environmental decisions. Its promotion within urban communities is widely acknowledged, requiring urgent attention, appearing on the agendas of many agencies, organizations and governments $[9,10]$. 'Sustainable development' now includes 'economic, social and ecological' work [11]. Some [12] regard this three-dimensional model as insufficient, lacking governance and other performance criteria. Urban sustainability therefore requires four pillars: social development, economic development, environmental management, and urban governance [13]. Paul James [14] points out that sustainability covers ecology, economics, politics and culture, intersecting with other social conditions, such as resilience, liveability, adaptation, innovation and reconciliation - all basic for positive social life. Ahmadi and Toghyani [15] argue that sustainable development strategies focus on five dimensions: economic, social, and ecological sustainability, spatial development, and cultural continuity. Arguably, sustainability has become a complex term applicable to most facets of life and necessary for improvements in the way inclusive development policies are designed and implemented [16].

\subsection{Urban governance as a tool for environmental sustainability}

Managing urban growth has become one of the most important challenges facing modern governments. As cities grow and evolve, their management becomes ever more complex. Research has also identified various barriers for the promotion of environmental sustainability. These include politics, the legal mechanism, institutional framework financial issues, technological and technical capacities [17,18]. Many authors [19] argue 
that unbalanced developments in growing cities are due to a lack of effective governance committed to sustainability. Abubakar and Aina [20] point out that public regulation of urban development caused deteriorations in environmental quality, thereby hindering sustainability. Although integrated planning regulation and implementation have long been considered central to environmental sustainability, they remain significant challenges because the current governance arrangements in many countries are ill suited to integrate spatial planning with long-term environmental sustainability [21].

As regards the promotion of urban and environmental governance, Riddell [22] points out that the most serious obstacle to sustainable development is the governance approach. This can be attributed to weak co-ordination between multiple stakeholders and agencies, which are a central element for achieving environmentally aware cities, yet whose decision-making process are not well integrated. Satterthwaite [4] says sustainability cannot be achieved via the technicalities of city planning: it is more important to inquire how government and other stakeholders can contribute to it. Good governance has the potential to regulate and enforce environmental legislation and other environmental measures [23]. Similarly, Cohen [24] argues that to address shifting urban opportunities and challenges effectively, it is urgent to build and support local government capacity to manage serious urban challenges, land resources and growing demands for rapid yet sustainable urbanization. Darnall and Kim [25] suggest that integrating a full range of environmental considerations, requires a central unit to address various urban and environmental issues. In line with these arguments, the researcher maintains that integrated urban governance must be considered when enhancing spatial planning regulations, ecological legislation, and other complex challenges. Moreover, all policies, projects, and proposals should be considered holistically.

On 20 October 2016, the Habitat III Conference in Quito on Housing and Sustainable Development adopted the 2030 Agenda for Sustainable Development. This represents a shared vision for a better and more sustainable future, providing guidance on achieving well-being for current and future generations in both developing and developed countries [26]. The agenda recommends governance as a key factor for sustainable and inclusive urbanization, enabling multiple environments for all actors playing roles in policy-making and implementation. It stresses reinvigoration of integrated urban planning and design frameworks, advising governments to rely on partnerships with non-governmental stakeholders to regulate development through ecological thinking. Governance should be considered when improving environmental legislation and related measures [27].

In summary, the role of governance in promoting the competence of public bodies in urban growth and sustainability has been widely discussed. Significant advances are being made in both academic research and in practice. As stressed in the current research [18] that promoting integration of the environment agenda into urban planning and management requires effective urban governance. In this article the researcher argues that without suitable governance arrangements the move towards sustainable inclusive urbanization cannot happen.

\section{Methodology}

The aim of this article is to explore the relationship between governance at different levels (national, regional and local) and environmental outcomes in Saudi Arabia. Based on existing contributions $[18,22,28]$ which argue that governance is central for environmental sustainability, we believe the launch of Saudi Vision 2030 and enactment of the National 
Transformation Program (NTP) will promote inclusive governance. This will improve nationwide productivity while enhancing the implementation of an environmental regime. To test this, a systematic literature and document review concerning participatory governance and environmental sustainability have been done, seeking new ideas and principles. In addition, empirical surveys have been conducted in three major cities in Saudi Arabia (Mecca, Medina, Jeddah) between December and April 2018. This survey focussed on gathering the perception of officials and professionals from both private and public sectors alongside important NGOs towards the quality of environmental governance in Saudi Arabia. Moreover, the author also participated in several seminars which focussed on the future of Saudi cities to promote the quality of life, while providing empirical material and evidence.

It is important to note that the investigator has worked as a consultant in the Technical Committee for supervision of the expansion of the twin holy mosques in Mecca and Medina and on preparation of the master plan for the central area in Medina between April 2013 and December 2018. The investigator is also a representative of the Technical Committee in King Abdulaziz University in the vision 2030 realization programme called the 'Enriching the Hajj and Umrah Experience Programme'. Accordingly, he is directly involved in studying several urban planning issues in coordination with Medina Development Authority, the Municipalities in Mecca, Jeddah and Medina. As well as relevant Ministries such as the Ministry of Municipal and Rural Affairs (MOMRA). Moreover, he has attended many workshops and seminars held periodically by governmental bodies related to urban planning and future development in these major urban centres. Among these seminars, the expansion of the Prophet's Mosque in Medina and the development of the central Area in Medina seminars organised by the Medina Development Authority in April 2018; the Future of Jeddah City organised by Jeddah Municipality in January 2018; and the development of Holy Sites in Mecca organized by the Mecca Chamber of Commerce in February 2018.

Employing a qualitative approach, data collection and in-depth interviews were conducted in order to explore the perceptions of experienced professionals and officials regarding challenges Saudi cities face in regulating urban development and protecting both the natural and urban environments (Sample size: 31), focused on senior executives from several governmental bodies, officials of consultant offices, universities, and important non-governmental organizations (NGOs). This was done through interviews in offices, cafés and hotels (Table 1). The selection was based on quota sampling through researcher choice and individual willingness to participate. The investigator used the saturation point, in which the collection of new data adds no further insights [29]. Regarding this concept, Mason points out that a large sample in qualitative research can be time-consuming and becomes repetitive and does not add anything to the issue under investigation.

From the literature review, the researcher scrutinized different themes linked to the promotion of environmental sustainability in the Kingdom. In line with these themes, semistructured interviews were prepared as tools to link governance with environmental sustainability. The in-depth interviews were digitally recorded and transcribed in order to generate a substantive code. After that, the investigator analysed and classified items into themes to develop a coding framework. These codes were then grouped into concepts and categorised to establish an analytical framework and demonstrate the findings. The questions in the semi-structured interviews include: 1) what constitutes environmental sustainability and what causes environmental degradation in Saudi cities? 2) How can 
public authorities handle environmental risks such as resource and water depletion, air and water pollution, land degradation and contamination, waste disposal etc. 3) Do current urban planning approaches and the establishment of a legal regime contribute to environmental sustainability and ensure zero-impact development? 4) Are the quality of governance and the creation of environmental authorities effective enough to achieve environmental sustainability and protection of the ecosystem for future generations? 5) To what extent do the current administrative reform initiatives and institutional mechanisms for environmental sustainability allow public participation and stakeholder engagement in environmental planning and governance? 6) What are the key environmental challenges and opportunities to shape actions towards environmental sustainability? How effective are Saudi Vision 2030 and NTP initiatives in promoting spatial planning and environmental governance? 7) Recommendations for improvements.

Table1. Participants of In-depth interviews

\begin{tabular}{lcccc}
\hline Participants & Number & Male & Female & Age \\
\hline Academic staff & 7 & 3 & 4 & $35-60$ \\
Urban Planning professional & 4 & 4 & - & $30-40$ \\
Environmental planning professional & 5 & 4 & 1 & $30-35$ \\
NGOs & 3 & 1 & 2 & $30-45$ \\
Developers & 1 & 1 & - & 55 \\
Local authorities & 6 & 5 & 1 & $35-45$ \\
Regional authorities & 2 & 2 & - & $40-45$ \\
Central authorities & 3 & 2 & 1 & $40-50$ \\
Total & 31 & 23 & 9 & $30-60$ \\
\hline
\end{tabular}

\section{Promoting environmental sustainability in Saudi cities}

To integrate environmental sustainability at the national, regional and local levels, the council of ministers and relevant agencies have embarked on several institutional reforms and environmental planning initiatives. These governmental bodies have established wellarticulated environmental laws aligned with national Basic Law and global sustainable development regulations within the general guidelines of the Environmental Assessment System of the Gulf Cooperation Council.

In 1975, in response to massive population growth, rising oil prices, and increasing income, successive reforms have established a central planning apparatus and ministries to regulate urban and rural development while overseeing public services. A Ministry of Planning (MOP) replaced the Central Planning Organization (CPO) and was empowered to regulate economic development. The provision of various public services associated with the economic boom necessitated the establishment of MOMRA, responsible for spatial planning, urban development, infrastructure, and public health. The responsibilities of the Municipal Agency under the Interior Ministry were assigned to MOMRA, which devised several administrative and planning systems alongside new local municipalities. MOMRA was made responsible for urban development, environmental health services, infrastructure provision, waste management, and the cleaning of urban and rural areas [30, 31].

In 2001 A Royal Decree enacted established the General Presidency of Meteorology and Environmental Protection (GAMEP) with responsibility for environmental protection 
conservation of natural resources, promotion environmental awareness, and environmental protection standards. These increasing concerns expanded governmental bodies interested in the environment from small units to an independent ministry linked to the Council of Ministers. For example, before GAMEP, there was a Meteorological Directory established in 1950 with responsibility for environmental protection; restructured in 1981 as the Meteorology Department, later the Meteorology and Environmental Protection Administration (MEPA), again in 2001 as the Presidency of Meteorology and the Environment (PME), its name changed in 2016 to the General Authority for Meteorology and Environmental Protection. It created the General Environmental Law in October 2001 within the framework of effective coordination with the relevant authorities in all environmental issues, to ensure public agencies and individuals abide by the Law. The General Authority undertakes responsibility for and commitment to Article 32 of the Basic Law of Governance of 1992 regarding environmental protection and the obligation to preserve natural resources and protect public health (PME 2001). It also plays a major role in coordinating with other governmental bodies with an interest in the environment, emphasizing the importance of coordination between relevant government institutions and agencies.

In 1994, after the Council of Ministers approved National Agenda 21, it set up the Environmental Protection Co-ordination Committee (EPCC) to regulate ecological planning and environmental preservation. This committee was renamed the Preparatory Committee for the Ministerial Committee for the Environment (PCMCE) and again renamed the Ministerial Committee for the Environment (MCE). It was headed by the Minister of Defense and established to serve as the national body responsible for drawing up environmental policies while coordinating all activities of agencies involved in related issues. Since then the Minister of Defence has been responsible for the environment, with the authority to issue rules for implementation. GAMEP and MOMRA with its municipalities are the two public agencies legally mandated to monitor and enforce legislation to ensure that effective environmental laws are carried out. In 2015, after endorsement of the UN SDGs, the government committed itself to meet them. A Royal Order tasked the Ministry of Economy and Planning (MEP) to put the goals into action by aligning them with national development plans. This created a dedicated Ministerial team to handle coordination with governmental apparatuses, linking goals to specific policies and programmes carried out by civil society partnerships [32].

\section{Saudi Vision 2030 and the adoption of the UN goals}

In April 2016, the Saudi cabinet endorsed Vision 2030, a wide-ranging economic and administrative reform programme designed to strengthen the economy through reduced dependence on oil. It would rationalize public spending while protecting vulnerable groups from negative economic outcomes. It was driven by fiscal pressures following decreasing oil prices, a budget deficit, and slow project progress. These hampered public sectors in regulating sustainable spatial and socio-economic developments. This necessitated new initiatives and reforms to public sector agencies [33]. The ambitious economic and administrative reforms were supported by an integrated governance model embracing several institutional structures to involve stakeholders from the private sector and non-governmental organizations. The reforms addressed major challenges that undermined the National Development Plans and Vision 2030 and pathways towards UN goals. Accordingly, several ministries were restructured, and other government and non-government organizations established [32] . Vision 2030 reflects the Kingdom's history and its core values. It is based 
on three thematic pillars - a vibrant society, a thriving economy and an ambitious nation to integrate all relevant dimensions (social, economic, environmental, spatial development and governance) advancing sustainable development holistically, thus making it the point of reference for all major decision-making processes. Vision 2030 encompasses 'strategic objectives, targets, outcome-oriented indicators and commitments that are to be achieved by the public, private and non-profit sectors in the Kingdom', together with implementation of spatial planning and environmental policies (Fig 1).
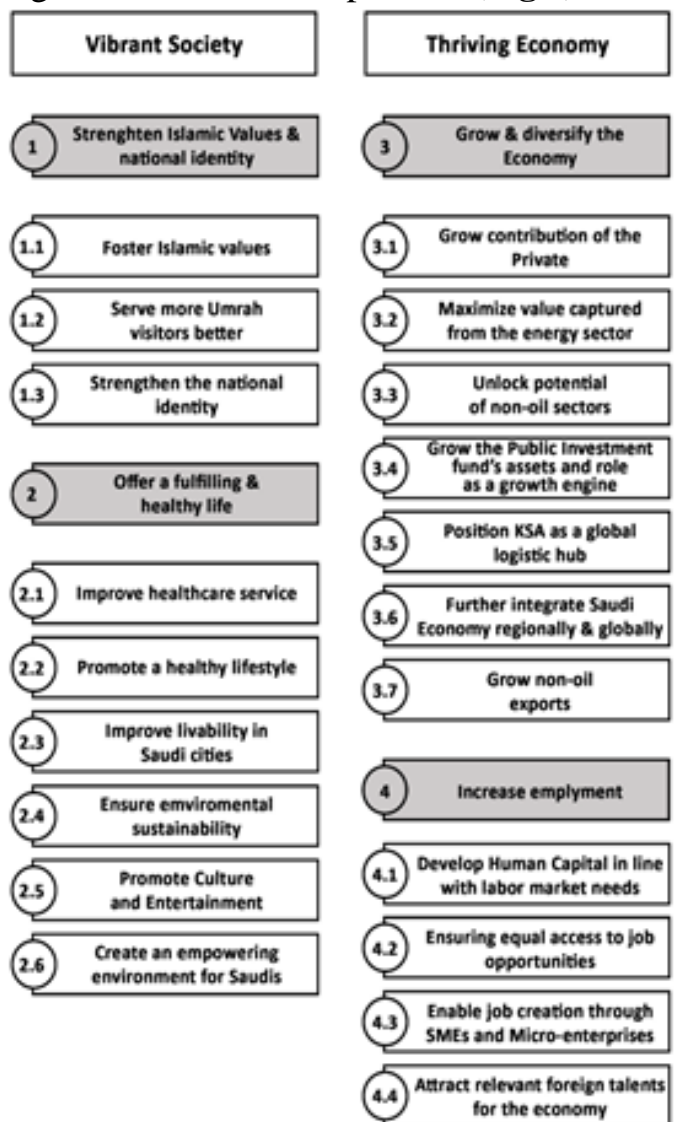

An Ambitious Nation
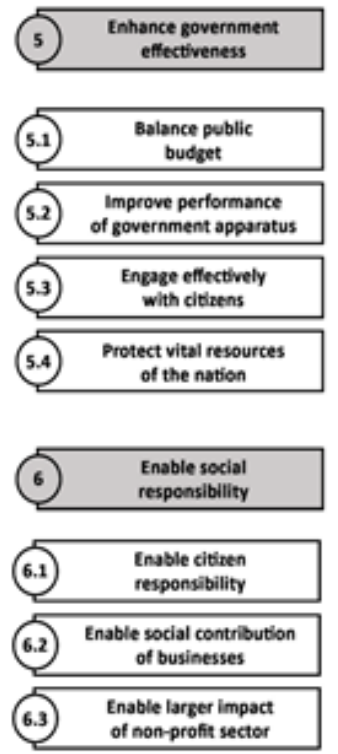

Enable larger impact
of non-profit sector

Fig. 1. Saudi Vision 2030, Strategic objectives. Source: Adopted from CEDA 2018.

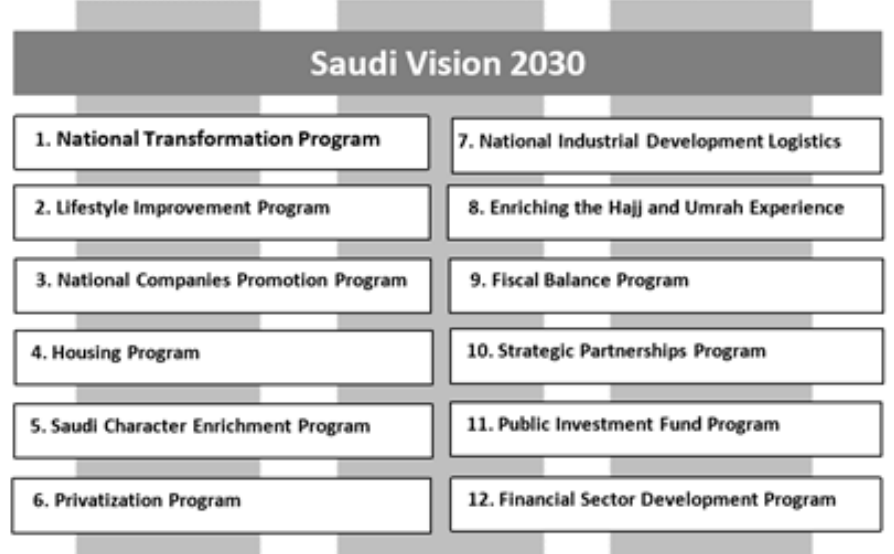

Fig. 2.The constructive programmes of the Saudi Vision 2030. Sources: Adopted from MEP 2018 
To support Vision 2030, the Council of Ministers tasked the Council of Economic and Development Affairs (CEDA) with establishment of a monitoring mechanism. To promote institutional and administrative capacities needed to achieve the ambitious goals of Vision 2030, the National Transformation Program 2020 (NTP) was launched by CEDA. The NTP sets targets and benchmarks for public sector agencies, establishing expert project management offices (PMOs) under the MEP to provide overall frameworks overseeing mega projects. The Vision Realization Offices (VROs) in ministries and government bodies in charge of regulating development were assigned responsibility to monitor progress in Vision 2030. Within the context of Vision 2030, NTP and eleven others constructive programmes have been launched by CEDA (Fig 2). These programmes aim to achieve the Vision's goal and to align SDGs with national strategies in various sectors [32]. For example, among the initiatives of the NTP, MEWA developed its Water Strategy and Environment Strategy to address the UN goals, holistically addressing social, economic and environmental dimensions. For another example, one of the major goals of Vision 2030 is to transform the country to access renewable energy sources instead of depending on fossil fuel. MEIMR and King Abdullah City for Atomic and Renewable Energy (KACARE) have a strategic objective to generate renewable energies such as atomic, solar and wind power by 2030 (Alshuwaikhat and Mohammed 2017). In 2017, the King Salman Energy City (SPARK) complemented KACARE 2010. Together, they form a global industrial hub for the energy sector, localizing new industrial and manufacturing services that support economic growth and improve the Kingdom's GDP [34]

To implement the goals of Vision 2030, programmes launched previously by various governmental sectors have been rescheduled and other new programmes established. These include the 'Future of Saudi Cities Programme', the 'Municipal Transformation Programme' (MTP), and, more recently, the 'Quality of Life Programme' 2020, launched in June 2018 to develop suitable activities to enhance the quality of life of individuals and families. MTP seeks to modernize the municipalities, considering diversification of investment opportunities, incorporating sustainable development principles and raising living standards in cities to reach Vision 2030 targets. MOMRA believes that enhancing the institutional and financial capacities of municipalities and sub-municipalities will increase participation by private sector and other stakeholders in taking charge of development.

The Future Saudi Cities Programme was launched by Royal Decree in 2013, tasking MOMRA to cooperate with the U.N. Human Settlement Programme (UN-Habitat). It has now been rescheduled to match the timeframe of NTP 2020 to achieve the Vision 2030 goals. This programme will provide better urban environments for the seventeen cities, integrating spatial planning with the Vision and UN SDGs. These include strengthening urban legislative and institutional frameworks, empowering localities through sustainable development initiatives, working to resolve contemporary challenges to improve the quality of life while reducing ecological footprints and hazards [32]. To bring the country towards environmental sustainability, Vision 2030 explicitly commits itself to safeguard the environment and natural resources. Several strategic environmental objectives have been enacted by MEWA, concerning matters such as natural vegetation and forest, greenhouse gas emissions, biodiversity, ecological footprints, and climate change (Fig 3). 


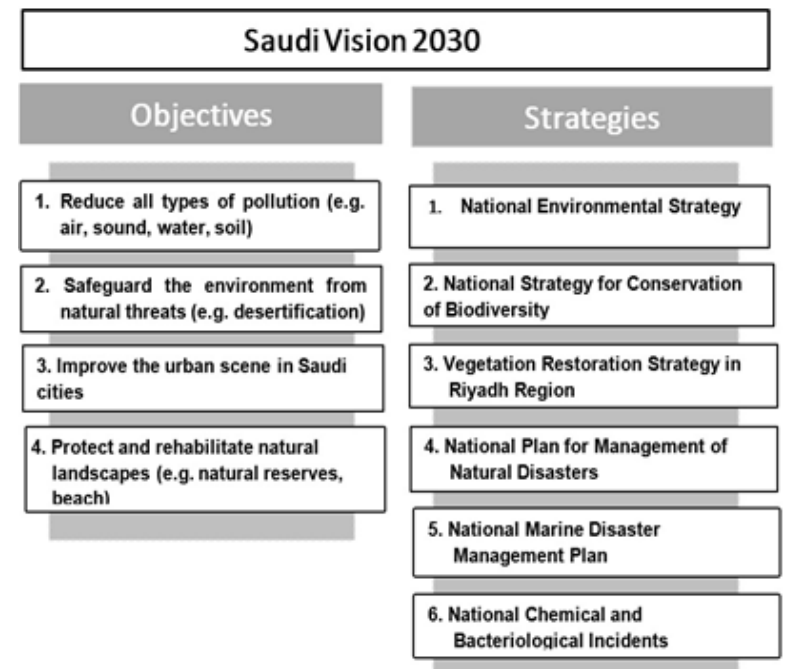

Fig. 3. Objectives and strategies of the Saudi Vision 2030 for achieving environmental sustainability.

In response to escalating hazards which become key barriers to social and economic development, Vision 2030 focuses on minimization of the environmental impact on cities, focusing on air quality, municipal waste management and pollutants, increasing green areas, using treated wastewater and mitigation of dust storms (GAMEP 2017). To create a healthy environment in cities, MOMRA and RCJY have established a modernized municipal waste management system. This has been structured to achieve parameters outlined by the NTP as a benchmark for measuring population satisfaction with pest-free cleanliness of cities and food safety [32].

In assessing how far sustainability is found in Vision 2030, Alshuwaikhat [35] has indicated that although its goals and objectives reflect the needs, desires and context of Saudi Arabia, they also align with the Sustainable Society Index (SSI) measures. This index is based on environmental, social and economic sustainability measures. It was developed by Van de Kerk and Manuel [36] and embraces indicators for measuring sustainability within 'five broad categories of personal development, clean environment, well-balanced society, sustainable use of resources and sustainable world'[35] (P. 3). They also point out that to ensure the success of Vision 2030, active involvement and empowerment of stakeholders at all levels alongside comprehensive and periodic assessment mechanisms are urgently needed. Current MEP assessments of Vision 2030 initiatives reveal a strong alignment between these and the $17 \mathrm{UN}$ goals in terms of targets and the time-framework. This will help incorporate the SDGs into government programmes and interventions. The assessments also reveal an urgent need to strengthen collaboration among different actors, enhancing the monitoring and performance evaluation to track national and sub-national progress [32].

\section{Key challenges for the promotion of environmental sustainability}

Concerns about environmental sustainability emerge from a study of the perceptions of experts in environmental sustainability in Saudi public and private agencies involved in urban planning and environmental issues. This regards environmental quality as affected by existing governance arrangements for regulating urban development and the protection of the natural environment and public health. Based on earlier research [4], [28] which provided improved insights into the importance of urban governance for integrating 
environmental concerns within spatial planning and development, the rearcher developed the themes and the questions of the in-depth interviews.

As indicted above, several agencies have been assigned responsibility city development regulation, environmental protection, and public health. Spatial planning regulations alongside the General Environmental Law and by-laws have been enacted to create a framework for developmental and environmental rules. These efforts have improved urban living conditions and reached several environmental targets such as pollution reduction and coastal management planning. However, these accomplishments have not yet achieved the ambitious environmental sustainability as the main pillar of development. The impact of interventions has not implemented the principles of the UN goals. Many environmental issues continue. These include environmental pressures, solid municipal waste, soil and groundwater pollution, depletion of non-renewable resources, exhaustion of wildlife, desertification, urban and marine destruction, polluting from land-based sources, including sewage and waste. These challenges continue to impede sustainable urban development and are considered barriers for effective implementation of environmental laws.

In the next finding, the researcher shows that key challenges for the promotion of environmental sustainability can be grouped into several main categories, as follows: growing demand for housing facilities, financial and institutional capacities, stakeholder engagement, legal and enforcement mechanism, progress monitoring technology and agency coordination in environmental issues - an overarching challenge. The researcher will probe these and other factors influencing environmental sustainability, outlining challenges to urban governance.

\subsection{Growing demand for housing and community facilities}

The implementation of ambitious national plans has accelerated demographic and urban growth. In 2014, the total number of cities reached 285. This produced several urban challenges. Among of these was intensification of demands for housing and services [32] . These demands have pressurized environmental capacity by increasing pollutants. The agencies in charge of environmental protection and public health are themselves pressurized [37].

In response to rapid growth, residential, commercial, and industrial development has sprawled out, destroying environmentally sensitive areas such as agricultural land, seashore, and mountains [38]. Despite efforts by MOMRA, GAMEP and other agencies to address environmental issues, city and environmental management remains unsatisfactory. Desalination plants have expanded, harming the marine environment. Similarly, heavy fuel oil for power urbanisation and industrialisation considerably stress existing energy supplies including electricity. Likewise, dramatic increases in car usage and industrial expansion alongside residential and commercial sectors, contributed to rising levels of greenhouse gases and polluted air. Some interviewees attribute this to a lack of planning policies addressing the conflict between competing land-use demands to ensure a balance between socio-economic development and environmental sustainability. Others participants confirm the result of previous research [39] which attributed this to weak governance, hindering collaboration between stakeholders and cross-sectoral challenges in implementing environmental laws.

\subsection{Institutional framework and enforcement mechanism}

Studies carried out by GAMEP over several years reveal a clear need to revise the current General Environmental Law. Evidence suggests that its weakness can be attributed 
to several factors. These include: a lack of consideration of national obligations towards international conventions ratified following the updated Environmental Law (2002); poor community engagement in environmental decision-making and monitoring processes for protection; weak coordination with MOMRA and other agencies in enforcement of the law; absence of specialized courts for environmental affairs; ephemeral encouragement of excellence in environmental performance through monitoring and control in management practice, which is more concerned with compliance[40].

Though legislative efforts seek to establish legislation and institutions enforcing the Environmental Law, lack of a holistic approach to address environmental issues and the fragmentation of responsibilities while individual issues are dealt with by single department or agencies made it difficult to establish a coherent legal regime ensuring integration of policies and programmes or encouraging multi-disciplinary cooperation $[41,42]$. The majority of interviewees indicate that despite the significant power that GAMEP, MOMRA and other governmental agencies have been given to impose penalties for violations, the absence of a clear legal framework containing tools for implementing urban policies and environmental regulations accompanies outdated land urban management methods that prevented the establishment of a coherent statutory system to enforce environmental and spatial planning regulations. This led to many environmental problems including unacceptable pressure on sensitive areas and destruction of ecosystems while failing to implement the SDGs.

Interviewees have confirmed the results of previous research [43], which indicates that, despite remarkable efforts by agencies to establish legal frameworks for environmental law, the country still suffers from weak enforcement powers. Weak enforcement is also linked to a lack of decisive and applicable laws rather than deciding to implement laws or not, or to a lack of coordination among the enforcement team [35]. This is apparent in poor waste disposal and marine degradation in coastal cities because crude oil, toxic chemicals and solid waste are dumped at sea. Enforcing environmental laws through agencies dedicated to the principles of sustainable development requires strong leadership and political will with a long-term vision of growth also demands coordination of multiple actors and sectors.

\subsection{Coordination of multiple actors and sectors}

As indicated in section three, MOMRA and GAMEP have appointed to address complex legal issues for urban development regulation, environmental management, natural resource conservation, and promotion of environmental awareness. Although these agencies played major roles in developing mature spatial planning policies and environmental laws alongside legal regimes, the quality of their management systems and urban policies remains far below the developed world. This is because their approaches are fragmented at both local and national levels based on conventional professional boundaries. Moreover, the environmental regime still lacks a comprehensive vision addressing the coordination of all involved public agencies. MOMRA is responsible for physical development. Through local municipalities, it prepares master plans and urban land policies. Unfortunately, preparation of these plans is usually carried out with while weakly integrated with other branches of ministries involved in environmental protection.

Similarly, GAMEP has been granted greater autonomy. It was challenging officials to foster inter-agency coordination and cooperation. This undermined the application and enforcement of environmental standards and spatial planning regulations. GAMEP officials had difficulty exchanging information to evaluate the state of the environment with other 
agencies. This is due to lack of a clear legal and institutional framework and the shortage of a qualified technical and enforcement cadre [38], [44].

Interviewees have confirmed that coordination between the two major agencies in charge of environmental protection is weak and limited to activities such as coastal projects. Although many studies have been undertaken by these two agencies, few have been implemented or approved at the local level. Respondents also indicates that most public and private agencies have far to go before they can implement laws. This is inevitable when single environmental issues are handled by individual organizations while ignoring interdependencies with other agencies, creating conflicts of interest and complexity in addressing cross-sector management.

\subsection{Public participation and stakeholder engagement}

Legislative efforts have sought to enable active participation by civil society stakeholders in the decision-making processes addressing environmental affairs. The urban governance structures and newly established regulatory and institutional frameworks drawn up in GAMEP and MOMRA reconfigure responsibilities for environmental challenges to enhance formal stakeholders' engagement at all stages, promoting sustainability. Unfortunately, progress lags behind expectation. Respondents have confirmed the result of previous studies [30] which reveal that among the factors constraining adaptation of new legislation to enable stakeholder participation is related to the absence of a clear institutional framework for this, without a systematic approach involving other actors working for environmental sustainability, while public sector agency officials resist new governance arrangements

In some cases, new arrangements for addressing issues (e.g. deterioration of the marine environment) were riddled with tensions because of the struggles between stakeholders over the meaning of 'engagement'. In others, differing opinions over sustainable development led to confusion about duties, identification, and prioritizing of stakeholders. Newly established organizations seldom consider the participation of stakeholders as part of daily operations in their core agencies, nor do they have expertise about sustainable innovation contributing to development. As a result, the engagement of a wide range of stakeholders hindered harmony between diverse interests, leading in turn to collisions of interest and conflicts that exacerbate the complexity of tackling environmental challenges.

\subsection{Progress monitoring technology}

Another significant challenge is ineffective monitoring mechanisms to assess progress in resolving key environmental issues presented in the General Environmental Law. GAMEP and other agencies have built administrative capacity to understand law enforcement and environmental monitoring. However, weaknesses in these mechanisms has not enabled these agencies to achieve targets such as the adopting UN goals. This may be due to a non-holistic approach for follow-up and evaluation of environmental quality, the disintegration of tasks and responsibilities of agencies, insufficient departmental knowledge and capacity. Monitoring of new developments and assessment of their environmental impact require periodic inspection of the socio-economic impact of the programmes. This requires a comprehensive monitoring framework for development activities. Comprehensive frameworks ensure appropriate reviews of the environment, showing how far the balance between sustainable economic development and 
environmental protection has been achieved. Periodic evaluations also require trained human resources for pollution monitoring and accurate data.

Although data availability and quality have steadily improved, current investigation of the integration of Vision 2030 with the SDGs indicates that in certain areas monitoring data are unavailable. Moreover, this investigation revealed that no monitoring data is collected at a national level for sharing with various state apparatuses. Several organisations collect data on air quality such as Saudi Aramco's Air Quality Monitoring \& Meteorology Network and the Royal Commission for Jubail and Yanbu (RCJY), these data are not integrated into a national database.

\subsection{Financial and institutional capacities}

Another significant challenge for environmental sustainability is the lack of adequate financial resources for government agencies (GAMEP and MOMRA) charged with implementing goals. The annual budgets allocated to them are large, but insufficient to manage national environmental protection activities. They are too low to activate environmental conservation programmes when compared to the size of the Kingdom. There is growing demand for socio-environmental infrastructures meeting the needs of fast-growing cities and the costs of programmes featured in the National Development Plans. This negatively affects their performance in enforcing the General Environmental Law regulations.

Spatial and environmental planning is highly dependent on financial resources. Adequate reserves are needed for agencies to function and invest in high quality emergency services, adaptable to changing circumstances. Previous researchers [39] confirm restrictions on qualified personnel, undermining institutional and administrative capacities. The impact of insufficient human and financial resources is clearly shown in discrepancies between environmental law and land policies and regulations and the lack of public awareness sustainability. Inadequate funding restricts effective collaboration between stakeholders and expansion of basic infrastructures for environmental mentoring, while impeding successful implementation of SDGs.

\section{Discussion}

This review suggests that an interest in environmental sustainability and public health protection began during Saudi Arabia's foundation. This is evident in the establishment of ministries and bodies such as MOMRA, MEWA and GAMEP to develop plans, policies and regulations to implement sustainable development. Following National Agenda 21 (1994) and establishment of the Environmental Protection Co-ordination Committee (EPCC), remarkable efforts were made to integrate the Agenda into national development strategies. Environmental laws were drafted, raising environmental awareness and restructuring governmental bodies, encouraging their departments to regulate environmental sustainability activities and socio-economic development according to basic national and international guidelines. This indicates governmental concern for integration between local and central administrative units. It also indicates that responsibilities assigned to governmental bodies went beyond data collection and environmental studies to develop protection standards and regulations, establishing mechanisms for enforcement. This was done through powers provided by the regulations for their areas of responsibility by training a legal cadre to improve environmental issues and promote public awareness. 
Regarding the question of how public authorities handle environmental risks such as resource and water depletion and implement the principles of environmental sustainability, it is important to note that two important steps have been taken by the government. The first followed its endorsement of the SDGs and the enactment of a Royal Order in 2015, delegating authority to the MEP to ensure activation and alignment of the national development plans with the UN goals. The second is the Cabinet endorsement of Saudi Vision 2030 in 2016 and the enactment of NTP 2020, tasking CEDA to facilitate the implementation of the vision and establish comprehensive governance mechanisms to reposition the country on the path to sustainability [32].

As regards the question of whether the quality of governance and the creation of environmental authorities are effective enough to achieve environmental sustainability and protection of the ecosystem for future generations, the findings of this research indicate that despite government efforts to address environmental issues and ecological footprints, there are still noticeable issues that hinder moves towards environmental sustainability. Based on documentary analysis and the perspectives of participants of in-depth interviews, six issues can be identified as undermining the quality of environmental sustainability in the Saudi context. As indicated in the previous section, these include growing demands for housing facilities, financial and institutional capacities, stakeholder engagement, legal and enforcement mechanisms, progress monitoring technology, and agency coordination in environmental issues.

Regarding the environmental issues in general and the environmental degradation of sensitive areas such as agricultural lands, the majority of respondents have attributed these to the rapid pace of urbanization and industrialization, and the growing demand for housing facilities. They have also attributed these issues to a lack of planning policies and effective environmental governance to cope with the issues. This, in turn, has made it difficult to handle environmental risks such as resource and water depletion alongside water pollution, land degradation and contamination, waste disposal, and more. This can be linked to the difficulty of addressing the conflict between competing land-use demands and the implementation of environmental laws. As argued previously [45] emphases on economic diversification and socio-economic development often override environmentalism.

As regards the question of how to implement current urban planning approaches and establish a legal regime to contribute to environmental sustainability and ensure zeroimpact development, the findings of this research show general dissatisfaction with the lack of integration between environmental concerns and spatial planning. This, in turn, resulted in weaknesses in both the institutional framework and the enforcement mechanism of both urban policies and environmental regulations. As they point out, this lack of a coherent statutory system to enforce environmental rules alongside poor coordination between GAMEP (tasked to enforce the General Environmental Law) and various authorities such as MOMRA hinders prosecution for breaches of the law and urban development regulations. In many cases it is necessary to provide evidence of culpability for officials in the higher central or regional authorities, rather than dealing with issues at the local level. This has led to costly and time-consuming legal cases.

As regards the issue of coordination between multiple actors and sectors, most interviewees said environmental governance still lacks strategic structures for multi-level and multi-agency collaboration. Interviewees confirmed the result of previous research [37, 45] conducted in the Saudi context. This research indicates that, although MOMRA and GAMEP agencies played major roles in developing mature spatial planning policies and 
environmental laws alongside legal regimes, the quality of their management systems and urban policies remains far below the prescribed goals of environmental sustainability. Issues such as the fragmentation of responsibility and weak coordination between these two major agencies in charge of environmental protection continue to exist. Their approaches fragment because of sector silos and their basis on conventional professional boundaries.

Moreover, the environmental regime still lacks a comprehensive vision addressing the coordination of all involved public agencies. This is due to an absence of a clear legal and institutional framework and the shortage of a qualified technical and enforcement cadre. Thus, improvements in institutional, legal and intervention frameworks are urgently needed in order to create a platform coordinating people who influence public amenity provisions and allocation of authorizations and resources [46]. Moreover, the findings revealed that no monitoring data are collected at a national level for sharing with various state apparatuses. Although MOMRA and GAMEP collect data on environmental issues such as air quality and water contamination, these data are not integrated into a unified database.

As regards the question of the extent to which the current administrative reforms allow public participation and stakeholder engagement in environmental planning and governance, the findings of this study reveal that legislative efforts have sought to enable active participation by civil society stakeholders and to enhance formal stakeholders' engagement at all stages, thereby promoting sustainability. But progress lags behind expectation because of an absence of a clear institutional framework for involving other actors working for environmental sustainability. This, in turn, hindered establishment of what the New Urban Agenda calls a platform for community participation [47]. Regarding issues of limited financial and administrative capacity, respondents clearly point out that inadequate resources have scaled down essential personnel, expertise, and financial arrangements. This has hampered public authorities in addressing national environmental protection activities and in implementing and monitoring the environmental conservation programmes when compared to the size of the Kingdom.

As for the question of how effective Saudi Vision 2030 and NTP initiatives are in promoting spatial planning and environmental governance, The findings confirm the result of other recent investigations [48] which indicate that the 2030 and NTP (with reforms) may be considered appropriate steps towards urban governance and environmental management progress. This is because Vision 2030 incorporates good governance principles as prerequisites for promoting positive planning. These include efficiency, effectiveness, transparency, accountability, and participation. As argued by Naturvårdsverket [23] good governance has the potential to develop and enforce an environmental legal framework. The Vision 2030 initiatives and their associated political reforms provide momentum for optimizing sustainable environmental development actions as crucial factors [40]. Darnall and Kim [25] say that integrating such efforts within agencies by establishing a united front is urgently needed to address inter-related spatial planning and ecological issues and help build punitive mechanisms to enforce environmental legal and institutional frameworks. These synergies would result in the establishment of an integrated approach and standardized operations for monitoring and evaluation to address all plans, rules and proposals simultaneously [49].

In summary, this study confirms recent research [20], [32], [39] conducted in this context, arguing that the current governance approach is ill suited for the integration of spatial planning policies and environmental laws with a long-term vision of sustainable 
development. This approach has had little effect on environmental actions and outcomes. As outlined in the literature [24], [44], [49], [50] sustainability rests on four pillars: social development, economic progress, environmental management, and urban governance. A lack of effective governance can be considered the most serious obstacle to sustainable development. The findings of this research show that the four important issues related to weak governance have undermined environmental sustainability can be identified as: lack of a clear institutional framework with enforcement mechanisms, weak coordination between multiple stakeholders and agencies, poor involvement of citizens and the private sector, and little progress in monitoring and evaluation.

\section{Conclusion}

The researcher has reviewed claims about solving sustainable development challenges in many natural and man-made habitats which still suffer from environmental damage, examining many opinions. Theoretically, the desire to implement sustainable development principles requires attention to four above-mentioned issues. Integrated governance can implement those principles. Researchers must inquire how government and other stakeholders can contribute to sustainability for these principles to be translated into policies and actions.

The findings of this research provide fresh insights on how concerns over environmental sustainability necessitated administrative reform initiatives, transforming modern agencies and bridging older literature on urban governance with recent work on shifts toward sustainability. Analysis of the empirical data shows significant structural barriers to the latter. Public agencies responsible for spatial planning regulations and environmental standards operate independently. Recently, government has realized the urgent need to promote urban governance regulating urban development and addressing environmental issues holistically. Despite restructuring the governance regime, making efforts to adopt sustainable development principles, actions still lag expectations. The fragmentation of responsibilities for environmental activities is caused by a lack of clear institutional and legal frameworks, discordant agency work. Weak stakeholder consultation and public participation and poor enforcement of policies and regulations have disincentivized effective governance and undermined efforts toward sustainability.

The researcher argues that high-level leadership and political determination will help realize Vision 2030 and UN goals, with good governance ensuring that sustainability principles are promoted. Successful implementation of environmental policies and regulations require the incorporation of periodic strategic environmental assessments in order to know to what extent the key performance indicators in the 2020 National Transformation Programme have been promoted [35]. Moreover, environmental concerns and environmental law prepared by GAMEP need to be integrated in strategic spatial planning (SSP) prepared by MOMRA and various municipalities. To achieve this, strategic Environmental Assessment (SEA) needs to be incorporated in the decision-making process in order to ensure that local environmental concerns are addressed. Equally, tackling management issues where the fragmentation of responsibilities and lack of co-ordination lead to duplication and a multiplicity of environmental regulations, makes it imperative to consider the role of legislation within an appropriate institutional and legal framework. Furthermore, agencies directly involved in environmental management such as MOMRA and GAMEP should be better equipped to improve their capabilities to enforce 
environmental regulations through periodic assessment of their work towards sustainability. These agencies need to launch awareness programmes and establish a comprehensive database of monitoring reports. Training programmes and activation of scientific research programmes and best practices are also urgently needed to ensure effective interventions to address urban complexity and ecological sustainability.

\section{REFERENCES}

[1] D. Pearce, Blueprint 3: Measuring Sustainable Development. London: Earthscan, 1993.

[2] R. Goodin, Green Political Theory. Cambridge: Polity, 1992.

[3] J. Terborgh, Making Parks Work: Strategies for Preserving Tropical Nature. Washington, D.C: Island Press, 2002.

[4] W. E. Rees, "Achieving Sustainablility: Reform or transformation," in The Earth Scan Reader:Sustainable Cities, D. Satterthwaite, Ed. London, Sterling VA: Earthscan, 1999.

[5] A. M. Mensah and L. C. Castro, "SUSTAINABLE DEVELOPMENT: A CONTRADICTION ?! by," no. November, 2004.

[6] J. Morelli, "Environmental Sustainability: A Definition for Environmental Professionals," J. Environ. Sustain., vol. 1, no. 1, pp. 1-8, 2011.

[7] K. Borsekova, K. Kourtit, and P. Nijkamp, "Smart development, spatial sustainability and environmental quality," Habitat Int., vol. 68, pp. 1-2, 2017.

[8] R. Goodland, "The Concept of Environmental Sustainability," Annu. Rev. Ecol. Syst., vol. 26, no. 1, pp. 1-24, 1995.

[9] R. Prizzia ed. 2007. . Edited by, .., "Sustainable development in an international perspective," Handbook of Globalization and the Environment (19-42). CRC Press, Boca Raton, 2007.

[10] R. C. Repetto, World Enough and Time: Successful strategies for resource managment. New Haven, CT: Yale University Press, 1986.

[11] A. J. Anselm, "China's Efforts in Sustainable Development: A Test Case for Nigeria's Environmental Sustainability Goals," Mod. Econ., vol. 8, no. 5, pp. 21-35, 2017.

[12] B. Anwar, Z. Xiao, S. Akter, and R.-U. Rehman, "Sustainable Urbanization and Development Goals Strategy through Public-Private Partnerships in a South-Asian Metropolis," Sustainability, vol. 9, no. 1940, pp. 1-26, 2017.

[13] UN-Habitat, "Urban Planning for city leader," United Nations Human Settlements Programme, Nairobi, 2013.

[14] K. A. Fox and T. K. Kumar, "The functional economic area: Delineation and implications for economic analysis and policy," Urban-regional economics, social system accounts, and ecobehavioral science: Selected writings of Karl A. Fox. Iowa State University Press, Ames, 1994.

[15] F. Ahmadi and S. Toghyani, "The Role of Urban Planning in Acheving Sustainable Urban Development," OIDA Int. J. Sustain. Dev., vol. 2, no. 11, pp. 23-26, 2011.

[16] E. DeNicola, O. S. Aburizaiza, A. Siddique, H. Khwaja, and D. O. Carpenter, "Obesity and public health in Kingdom of Saudi Arabia," Rev. Environ. Health, vol. 30, no. 3, pp. 191-205, 2015.

[17] S. Malekpour, R. R. Brown, F. J. de Haan, and T. H. F. Wong, "A diagnostic strategic planning intervention for sustianable development," Manuscr. Submitt. Publ., vol. 63, pp. 58-69, 2017.

[18] and L. S. Gustafsson, Sara, Brita Hermelin, "ntegrating environmental sustainability into strategic spatial planning: the importance of management," J. Environ. Plan. Manag.

[19] N. Devas et al., Urban governance, voice and poverty in the developing world. London: Earthscan, 2004.

[20] I. R. Abubakar and Y. A. Aina, "Achieving Sustainable Cities in Saudi Arabia: Juggling the Competing Urbanization Challenges," Population Growth and Rapid Urbanization in the Developing World. IGI Global, PA, 2016.

[21] FAO, "Land resource planning for sustainable land management," Food and Agriculture Organization of the United Nation, Rome, 2017.

[22] R. Riddell, Sustainable Urban Planning Tipping the Balan. 2004.

[23] Naturvårdsverket, The role of governance for improved environmental outcomes, no. september. 2012. 
[24] B. Cohen, "Urbanization in developing countries: Current trends, future projections, and key challenges for sustainability," Technol. Soc., vol. 28, pp. 63-80, 2006.

[25] N. Darnall and Y. Kim, "Which Types of Environmental Management Systems Are Related to Greater Environmental Improvements?," Public Adm. Rev. Vol. 72, Iss. 3, pp. 351-365, vol. 72, no. 3, pp. 351-365, 2012.

[26] UN, "New Urban Agenda," United Nation, New York, 2017.

[27] DIIS, "Urban governance and sustainable development: Cities on the agenda," Danish Institute for International Studies, Copenhagen, 2016.

[28] P. Healey, "Creativity and Urban Governance," Plan. Rev. , vol. 40, no. 158, pp. 11-20, 2004.

[29] M. Mason, "Sample size and saturation in $\mathrm{PhD}$ studies using qualitative interviews," in Forum Qualitative Sozialforschung/Forum: Qualitative Social Research, 2010, vol. 11, no. 3.

[30] K. N. Mandeli, "Promoting public space governance in Jeddah, Saudi Arabia," Cities, vol. 27, no. 6, 2010.

[31] M. Aljoufie, "Toward integrated land use and transport planning in fast-growing cities: The case of Jeddah, Saudi Arabia," Habitat Int., vol. 41, no. 2014, pp. 205-2015, 2014.

[32] MEP, "Sustainable Development Goals 1st Voluntary National Review Kingdom of Saudi Arabia," Minister of Economy and Plannin, New York, 2018.

[33] CEDA, "KSA Vision 2030: Strategic Objectives and Vision Realization Programs," The Council of Economic and Development Affairs , Riyadh, Saudi Arabia, 2018.

[34]Argaam, "A look at King Salman Energy Park project," Argaam Financial News, Dubai, United Arab Emirates.

[35] H. M. Alshuwaikhat and I. Mohammed, "Sustainability Matters in National Development VisionsEvidence from Saudi Arabia's Vision for 2030," Sustainability, vol. 9, no. 408, pp. 1-15, 2017.

[36] G. Van-de-Kerk and A. R. Manuel, "A comprehensive index for a sustainable society: The SSI-The Sustainable Society Index," Ecol. Econ., vol. 66, pp. 228-242, 2008.

[37] T. Husain and A. A. Khalil, "Environment and Sustainable Development in the Kingdom of Saudi Arabia: Current Status and Future Strategy," J. Sustain. Dev. , vol. 6, no. 12, 2013.

[38] F. S. Al-Shihri, "Impacts of large-scale residential projects on urban sustainability in Dammam Metropolitan Area, Saudi Arabia," Habitat Int., vol. 56, no. 2016, pp. 201-211, 2016.

[39] F. K. Alturki, "Promoting Sustainable Development Through Environmental Law: Prospects for Saudi Arabia," Pace University School of Law, USA, 2015.

[40] GAMEP, "The State of the Environment (2017) Responsibilities and achievements," The General Authority for Meteorology and Environmental Protection, Saudi Arabia, Riyadh, 2017.

[41] K. N. Mandeli, "The realities of integrating physical planning and local management into urban development: A case study of Jeddah, Saudi Arabia," Habitat Int., vol. 32, no. 4, 2008.

[42] J. Alzahrani and M. W. Emsley, "The impact of contractors' attributes on construction project success: A post construction evaluation,” Int. J. Proj. Manag., vol. 31, no. 2, pp. 313-322, 2013.

[43] A. Al-Yami and A. Price, "An overview of sustainability in Saudi Arabia.," Joint International Conference on Construction Culture, Innovation, and Management (CCIM 2006): Sustainable Development through Culture and Innovation, 26-29 November 2006. Dubai, United Arab Emirates, pp. 109-119, 2006.

[44] K. N. Mandeli, "New public governance in Saudi cities: An empirical assessment of the quality of the municipal system in Jeddah," Habitat Int., vol. 51, 2016.

[45] D. Alzahrani and H. Alqasmi, "Protecting the Biodiversity of the Arabic Gulf's Coastal Waters from Agricultural and Industrial Runoff Case Study-Saudi Arabia," Int. J. Soc. Sci. Humanit., vol. 3, no. 1, pp. 62-65, 2013.

[46]P. Healey, "On creating the "city' as a collective resource," Urban Stud., vol. 39, no. 10, pp. 1777-1792, 2002.

[47] UN-Habitat, " Global Activities Report 2017 : Strengthening partnerships in support of the New Urban Agendaand the Sustainable Development Goals," UN-Habitat, Nairobi, 2017.

[48] khalid Mandeli, "The Impact of Unban Governance on the Quality of Public Services in Saudi Cities ,"JKAU Env. Des. Scince, vol. 11, pp. 1-16, 2017.

[49] J. Artiola, I. L. Pepper, and M. L. Brusseau, Environmental Monitoring and Characterization. Burlington: Elsevier, 2004.

[50]D. Mitlin, “Sustainable Development: A Guide to the Literature," Environ. Urban., vol. 4, no. 1,pp. 111-124, 1992. 


\section{التتمية المستدامة والحوكمة في المدن السعودية}

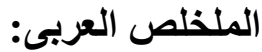

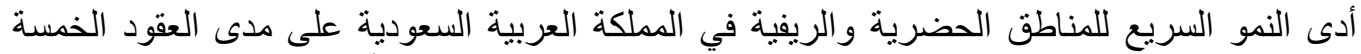

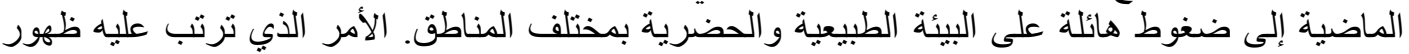

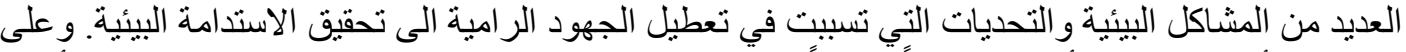

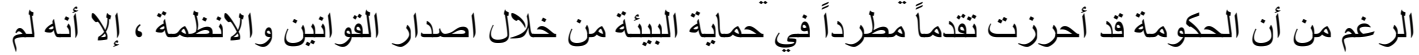

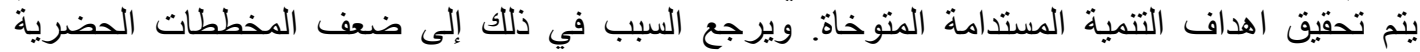

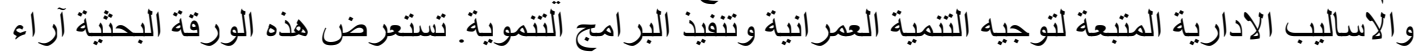

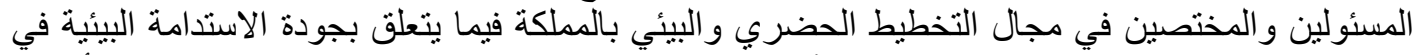

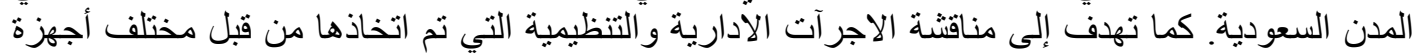

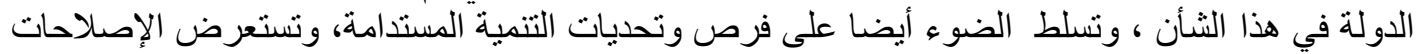

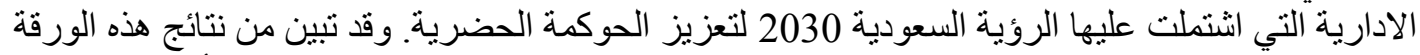

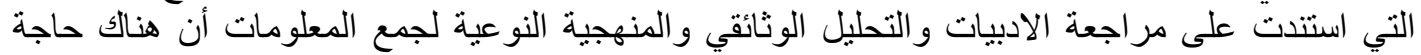

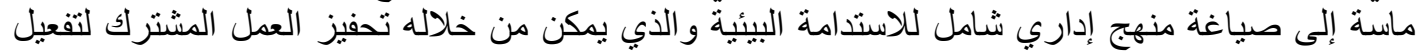

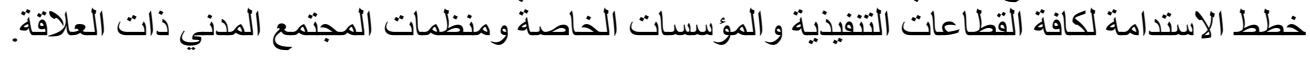

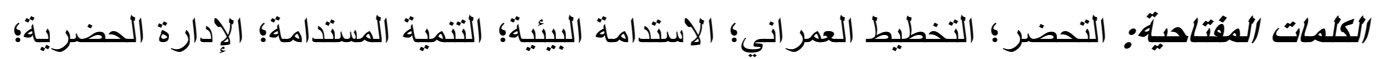
المملكة العربية السعودية المية المبات 